\title{
Access to Essential Contraception, Family Planning, and Safe Motherhood Services During COVID-19 Pandemic: Single Secondary Level Care Hospital Experience
}

\author{
Jayanta Kumar BISWAS ${ }^{1}$, Soumen Das PODDAR ${ }^{2}$, Ganesh SARAVAGI ${ }^{3}$, Ajith NILAKANTAN ${ }^{4}$ \\ Punjab, India
}

\begin{abstract}
OBJECTIVE: During the COVID-19 pandemic, more precisely as a result of restrictions on movement and continuing altered perception of essential health care services, women's health is disproportionately affected due to reduced access to services as per reports and statements made by different global and national level Government and non-government agencies. We aimed to evaluate the health care impacts related to contraception, family planning, and safe motherhood in an Indian Armed Forces secondary level care hospital during the COVID-19 pandemic.
\end{abstract}

STUDY DESIGN: Immediate health care effect on women's sexual and reproductive life during pandemic months (April to August of the year 2020) is analyzed through a retrospective observational cohort study in a single Indian Armed Forces secondary level care hospital experience.

RESULTS: It has shown more late reported unintended pregnancies requiring surgical intervention, more late-registered antenatal cases and consequently delayed essential evaluations, increased trend in high-risk cases requiring in-patient care, and reduced access to contraception and family planning services in comparison to those in the previous two years.

CONCLUSION: Considering these negative impacts noted in this observation, with the help of policymakers, government, and other non-government agencies, all services should be made available to women including un-interrupted out-patient and in-patient care services in all hospitals, along with continued basic infection prevention and control precautions to both clientele and health care workers. Telemedicine can also play a supplementary role in various aspects of women's health to avoid upcoming population explosion and for better maternal-child health care.

Keywords: Antenatal care, Contraception, COVID-19, Family planning, Pandemic

Gynecol Obstet Reprod Med 2022;28(1):69-75

${ }^{1}$ Obstetrics and Gynaecology Armed Forces Medical Services Military Hospital, Pathankot, Punjab, India

2 Obstetrics and Gynecology Armed Forces Medical Services Command Hospital, Chandimandir, India

${ }^{3}$ Radiodiagnosis Armed Forces Medical Services Military Hospital, Pathankot, Punjab, India

${ }^{4}$ Head and Neck Oncosurgery Armed Forces Medical Services Military Hospital, Pathankot, Punjab, India

Address of Correspondence: Jayanta Kumar Biswas1

Obstetrics and Gynaecology Armed Forces Medical Services

jayantabiswas1977@gmail.com,

Military Hospital, Pathankot, Punjab, India,

Submitted for Publication: 19.01.2021 Revised for Publication: 13.02.2021

Accepted for Publication: 12.03.2021 Online Published: 26.04.2021

ORCID IDs of the authors: JKB: 0000-0001-6005-4762,

SDP: 0000-0001-6228-1985, GS: 0000-0002-5037-6503,

$A N$ : 0000-0002-2523-6138

\begin{tabular}{|c|c|}
\hline \multirow{3}{*}{ 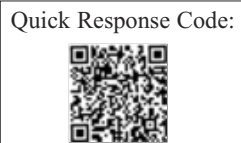 } & Access this article online \\
\hline & $\begin{array}{l}\text { Website: www.gorm.com.tr } \\
\text { e- mail: info@gorm.com.tr }\end{array}$ \\
\hline & DOI:10.21613/GORM.2021.1184 \\
\hline
\end{tabular}

How to cite this article: Biswas JK. Poddar SD. Saravagi G. Nilakantan A. Access to Essential Contraception, Family Planning, and Safe Motherhood Services During COVID-19 Pandemic: Single Secondary Level Care Hospital Experience. Gynecol Obstet Reprod Med. 2022;28(1):69-75

\section{Introduction}

World Health Organization (WHO) had declared COVID19 disease as pandemic on 11 March 2020. A global "Lockdown" with information on COVID-19 related mathematical data had taken over the world health care services ignoring essential health care services.

Antenatal care (ANC) is the systematic supervision of a pregnant woman and its objective is to ensure a normal pregnancy with the delivery of a healthy baby from a healthy mother (1). WHO made a comprehensive guideline on routine ANC for pregnant women and adolescent girls in 2016, recommending eight "contact" models to improve maternal, fetal, and newborn outcomes through evidence-based perinatal morbidity and mortality data (2).

Contraception, family planning including abortion services are always considered essential services worldwide. Unsafe abortions account for $8 \%$ of the maternal mortality rate in India, related to many factors like social, policy implemen- 
tations, economic, and accessibility to services $(3,4)$. Comprehensive abortion care is an integral component of efforts made by Govt. of India (GoI) to bring down maternal morbidity and mortality through different policies and legalization from time to time (4).

Due to the expected impacts of the COVID-19 pandemic by delaying in seeking, accessing, and receiving care (the three delays)-an increased burden of morbidity and mortality related to undesirable pregnancy outcomes has an overwhelming impact (5).

WHO survey over two-thirds of 103 countries between mid-May and early July 2020, reported disruptions of family planning and contraception services. A report by the Foundation for Reproductive Health Services India estimated that the pandemic could lead to an additional 8,34,042 unsafe abortions and 1,743 maternal deaths.

With this background, it is important to find any effects on the safe reproductive and sexual life of women due to COVID-19 pandemic restrictions. We conducted this study to analyze the immediate health care impacts related to altered provisioning of contraception, family planning, and safe motherhood services during the midst COVID-19 pandemic from April to August 2020 in a secondary level care defense hospital in India entitled to serving and ex-servicemen as well as their dependents.

\section{Material and Method}

\section{Study design and place of study with the study period}

The retrospective observational cohort study was conducted in a secondary level care hospital catering to defense service personnel, ex-servicemen, and their dependents, (for the year 2018, 2019, till August 2020 including the pandemic period of April to August of 2018-2020) with an aim to endpoint assessments in various denominators like delivery rate, OPD and IPD loads, mortality data, high-risk pregnancies, different ultrasonography (USG) modalities, medical termination of pregnancies, and various family planning services parameters.

\section{Single secondary level care hospital experience}

About $3 / 5^{\text {th }}$ of the clientele load to this hospital are dependents of serving personnel posted nearby, about $2 / 5^{\text {th }}$ are native entitled dependents and a few are referred from peripheral primary care level hospitals of around 100-kilometer radius area.

As far as obstetrics and gynecology services provided to clientele in this hospital is concerned, in the year 2019 onwards a lot of modern equipment was available. Advanced monitoring and surgical equipment along with contemporary facilities for diagnostic and management facilities were available.

During the pandemic times (April- August 2020), all de- partments of this hospital were fully operational and the Department of Obstetrics \& Gynecology had even extended the services through disseminating basic ANC monitoring by placing fetal monitoring equipment to peripheral medical facilities under the supervision of paramedics and by the implementation of telemedicine and social media platform not only to clienteles but also to health care professionals of peripheral primary care medical facilities as per guidelines of International Federation of Gynecology and Obstetrics (FIGO) statement dated 30 March 2020 (6).

\section{Results}

Various aspects of safe motherhood, contraception, and family planning services are enlisted in different tables and figures as specified. The data were analyzed by the simple comparison of monthly averages (arithmetic mean) whenever deemed necessary.

Delivery rate, out-patient care, and in-patient care, load including mortality data

Delivery rate, OPD, and IPD loads of this hospital are compared for the last 3 years including this year's COVID-19 pandemic days. The delivery rate is only marginally reduced in the year 2020 including during the pandemic period under observation in respect to previous years. A lesser number of patients had reported OPD services in 2020, more so during pandemic time compared to previous years. Monthly IPD load throughout the year in all the years under observation with comparison to that of during pandemic months are almost similar (Table I).

The conversion rate from OPD to IPD is increased gradually over the last 3 years (2018-8.62\%; 2019-18.26\% and till August 2020-19.48\%). It is even having a similar trend during April-August in all these 3 years (2018-8.3\%; 2019-18.40\%; 2020-20.74\%).

Maternal mortality and still-birth data are also compared and not much difference noted during the period of observations and also in previous years (Table II).

172 high-risk cases had reported very late in their pregnancy and subsequently delivered during pandemic days. More common obstetric co-morbidities observed at delivery in that time frame were gestational diabetes mellitus, hypertensive disorders in pregnancy, fetal growth restrictions, oligohydramnios, intrahepatic cholestasis in pregnancy, anemia, bad obstetric history, preterm labor, and preterm premature rupture of membrane (PPROM). Almost all kinds of comorbid cases reported are higher in numbers in comparison to previous years, but an increase in un-booked cases with no prior proper ANC visits, fetal growth restriction, and/or oligohydramnios cases are very alarming (Table III). 
Table I: Comparative data on Delivery/OPD/IPD load: 2018-2020 (till August)

\begin{tabular}{|c|c|c|c|c|c|c|c|}
\hline \multicolumn{2}{|l|}{ Services } & $\begin{array}{l}2018 \\
\text { (Jan- Dec) }\end{array}$ & $\begin{array}{l}2019 \\
\text { (Jan-Dec) }\end{array}$ & $\begin{array}{l}2020 \\
\text { (Jan-Aug) }\end{array}$ & $\begin{array}{l}2018 \\
\text { (Apr-Aug) }\end{array}$ & $\begin{array}{l}2019 \\
\text { (Apr-Aug) }\end{array}$ & $\begin{array}{l}2020 \\
\text { (Apr-Aug) }\end{array}$ \\
\hline \multirow{2}{*}{ Delivery load } & Numbers & 1502 & 1485 & 903 & 589 & 595 & 547 \\
\hline & Monthly average & 125.17 & 123.75 & 112.88 & 117.80 & 119.00 & 109.40 \\
\hline \multirow{2}{*}{ OPD load } & Numbers & 29366 & 27266 & 15466 & 13044 & 11757 & 8954 \\
\hline & Monthly average & 2447.17 & 2272.17 & 1933.25 & 2608.80 & 2351.40 & 1790.80 \\
\hline \multirow{2}{*}{ IPD load } & Numbers & 2532 & 4981 & 3013 & 1087 & 2163 & 1857 \\
\hline & Monthly average & 211.00 & 415.08 & 376.63 & 217.40 & 432.60 & 371.40 \\
\hline
\end{tabular}

OPD: Out-patient care. IPD: In-patient care

Table II: Comparative mortality data: 2018- 2020 (till August)

\begin{tabular}{lcccccc}
\hline Mortality data & $\mathbf{2 0 1 8}$ (Jan- Dec) & $\mathbf{2 0 1 9}$ (Jan-Dec) & $\mathbf{2 0 2 0}$ (Jan-Aug) & $\mathbf{2 0 1 8}$ (Apr-Aug) & $\mathbf{2 0 1 9}$ (Apr-Aug) & $\mathbf{2 0 2 0}$ (Apr-Aug) \\
\hline Maternal mortality & 01 & $\mathrm{Nil}$ & $\mathrm{Nil}$ & 01 & $\mathrm{Nil}$ & $\mathrm{Nil}$ \\
Stillbirth & 11 & 09 & 04 & 03 & 03 & 03 \\
\hline
\end{tabular}

Table III: Comparative high-risk cases related data: 2018-2020 (till August)

\begin{tabular}{|c|c|c|c|c|c|c|}
\hline Co-morbidity & (Jan- Dec) & 2019 (Jan-Dec) & 2020 (Jan-Aug) & 2018 (Apr-Aug) & 2019 (Apr-Aug) & 2020 (Apr-Aug) \\
\hline GDM & 69 & 73 & 49 & 23 & 28 & 29 \\
\hline $\mathrm{PIH}$ & 47 & 51 & 45 & 18 & 19 & 20 \\
\hline FGR/Oligohydramnios & 13 & 19 & 33 & 9 & 7 & 20 \\
\hline $\mathrm{IHCP}$ & 62 & 69 & 42 & 25 & 27 & 30 \\
\hline Anemia & 25 & 31 & 26 & 12 & 13 & 16 \\
\hline $\mathrm{BOH}$ & 19 & 17 & 13 & 7 & 9 & 10 \\
\hline Preterm labor & 31 & 40 & 32 & 16 & 21 & 19 \\
\hline PPROM & 28 & 32 & 20 & 9 & 15 & 8 \\
\hline Un-booked case & 44 & 46 & 50 & 21 & 20 & 37 \\
\hline Others & 40 & 38 & 25 & 22 & 24 & 20 \\
\hline
\end{tabular}

GDM: Gestational diabetes mellitus, PIH: Hypertensive disorders in pregnancy, FGR: Fetal growth restrictions, IHCP: intrahepatic cholestasis in pregnancy, BOH: Bad obstetric history, PPROM: Preterm premature rupture of membrane

\section{Obstetric ultrasonography modalities}

Increased number of ANC cases had reported for firsttrimester nuchal translucency/ nasal bone scan (NT/NB scan) and attempted anomaly scan beyond 24 weeks of gestation this year, more so during pandemic months but there was a decrease in routine anomaly scans (usually done at 18-20 weeks of gestation) in comparison to previous years. A similar trend is noted for monthly averages as well (Table IV).

Table IV: Comparative data on obstetric ultrasonography modalities:2018-2020 (till August)

\begin{tabular}{|c|c|c|c|c|c|c|c|}
\hline \multicolumn{2}{|l|}{ Services } & \multirow{2}{*}{$\begin{array}{l}2018 \\
\text { (Jan-Dec) } \\
38\end{array}$} & \multirow{2}{*}{$\begin{array}{l}2019 \\
\text { (Jan-Dec) } \\
44\end{array}$} & \multirow{2}{*}{$\begin{array}{l}2020 \\
\text { (Jan-Aug) } \\
38\end{array}$} & \multirow{2}{*}{$\begin{array}{l}2018 \\
\text { (Apr-Aug) } \\
22\end{array}$} & \multirow{2}{*}{$\begin{array}{l}2019 \\
\text { (Apr-Aug) } \\
16\end{array}$} & \multirow{2}{*}{$\begin{array}{l}2020 \\
\text { (Apr-Aug) } \\
28\end{array}$} \\
\hline & Numbers & & & & & & \\
\hline NT/NB scan & Monthly average & 3.17 & 3.67 & 4.75 & 4.40 & 3.20 & 5.60 \\
\hline Anomaly scan & Numbers & 1686 & 1736 & 1014 & 646 & 728 & 698 \\
\hline (18-20 weeks of gestation & Monthly average & 140.50 & 144.67 & 126.75 & 129.20 & 145.60 & 139.60 \\
\hline \multirow{2}{*}{$\begin{array}{l}\text { Attempted anomaly scan } \\
\text { (>24 weeks of gestation) }\end{array}$} & Numbers & 51 & 64 & 117 & 35 & 46 & 79 \\
\hline & Monthly average & 4.25 & 5.33 & 14.63 & 7.00 & 9.20 & 15.80 \\
\hline \multirow{2}{*}{ Other obstetric scans } & Numbers & 446 & 476 & 311 & 234 & 225 & 183 \\
\hline & Monthly average & 37.17 & 39.67 & 38.88 & 46.80 & 45.00 & 36.60 \\
\hline
\end{tabular}

NT/NB: Nuchal translucency/ nasal bone 


\section{Abortion services}

Medical and surgical methods of abortion services during the $1^{\text {st }}$ and $2^{\text {nd }}$ trimester, contraception, and family planning services provided by this hospital are compared for the last three years including the current year (Table V and VI).

During pandemic times also the contraception and family planning services continued through maintaining the supply chain of barrier contraception (condom) and oral contraceptive pills (OCPs) to registered eligible couples of dependent units through Lady Health Visitor (LHV) keeping FIGO statement dated 13 April 2020 in mind (5).

Observations in our study showed lower monthly rates of the clientele were able to avail medical, medical termination of pregnancy (MTP) facility not only throughout 2020 but also significantly lower during pandemic months in comparison to previous years. On the other hand, data for surgical MTP is having the opposite trend (Figure 1).

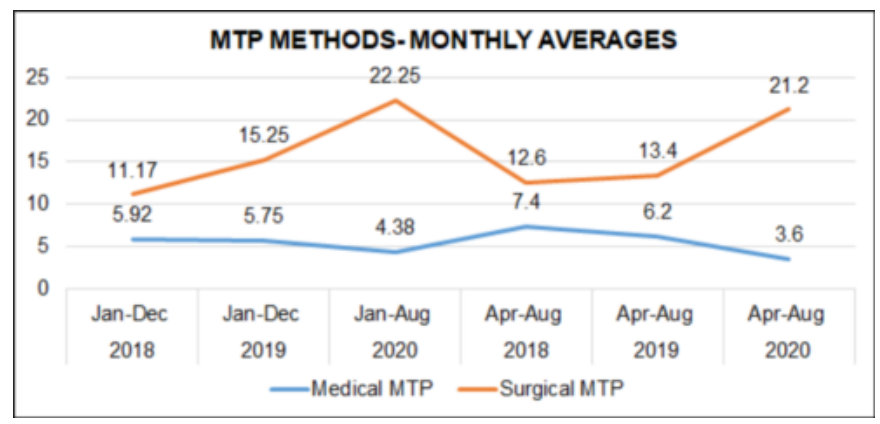

Figure 1: Comparative monthly averages of MTP services: 2018- 2020 (till August)

There is a little rise in the second-trimester abortion rate in the current year and more significantly in the pandemic months in respect to other months of the year. Interesting data is related to the contributing factor to it. A major cause of mid- trimester abortions this year are severe early-onset oligohydramnios, anhydramnios due to late reported long-standing PPROM, and even contraception failure cases. This year $11 / 18$ cases had a history of poor availability of required ANC visits; whereas in previous years most common causes weremajor congenital malformation with serious consequences to life if delivered at term.

\section{Contraception and family planning services}

As condoms and OCPs are being distributed to registered eligible couples throughout, services related to these modalities are not affected in the last 3 years even on pandemic days. Both male and female sterilization surgeries are significantly reduced this year and more so during pandemic days (Table VI). Almost 50\% reduction in comparison to previous years in case of tubectomy was noted; in fact, no vasectomy was performed in pandemic time this year (Figure 2).

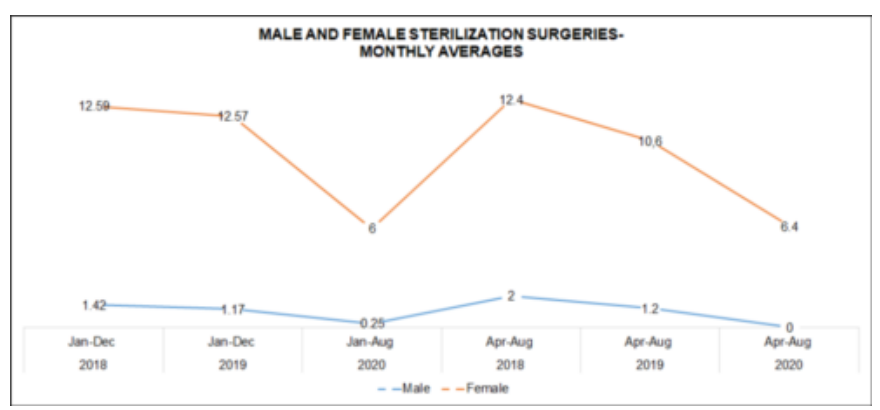

Figure 2: Comparative monthly averages of male and female sterilization surgeries: 2018-2020 (till August)

\section{Discussion}

As there was no such study conducted in the recent past on the issue under consideration with comparison to past data in an Indian Armed Forces hospital, we will discuss the COVID19 impact in respect to different international and national surveys with our findings.

Table V: Comparative data on abortion services: 2018-2020 (till August)

\begin{tabular}{|c|c|c|c|c|c|c|c|}
\hline \multicolumn{2}{|l|}{ Services } & \multirow{2}{*}{$\begin{array}{l}2018 \\
\text { (Jan- Dec) } \\
71\end{array}$} & \multirow{2}{*}{$\begin{array}{l}2019 \\
\text { (Jan-Dec) } \\
69\end{array}$} & \multirow{2}{*}{$\begin{array}{l}2020 \\
\text { (Jan-Aug) } \\
35\end{array}$} & \multirow{2}{*}{$\begin{array}{l}\begin{array}{l}2018 \\
\text { (Apr-Aug) }\end{array} \\
37\end{array}$} & \multirow{2}{*}{$\begin{array}{l}\begin{array}{l}2019 \\
\text { (Apr-Aug) }\end{array} \\
31\end{array}$} & \multirow{2}{*}{$\begin{array}{l}2020 \\
\text { (Apr-Aug) } \\
18\end{array}$} \\
\hline & Medical method & & & & & & \\
\hline $1^{\text {st }}$ Trimester MTP & Surgical method & 134 & 183 & 178 & 63 & 67 & 106 \\
\hline \multirow{2}{*}{$2^{\text {nd }}$ Trimester MTP } & Medical method & 25 & 26 & 18 & 11 & 18 & 18 \\
\hline & Surgical method & Nil & & & $\mathrm{Nil}$ & & \\
\hline
\end{tabular}

MTP: Medical termination of pregnancy

Table VI: Comparative data on contraception and family planning services: 2018-2020 (till August)

\begin{tabular}{|c|c|c|c|c|c|c|}
\hline Services & (Jan- Dec) & 2019 (Jan-Dec) & 2020 (Jan-Aug) & 2018 (Apr-Aug) & 2019 (Apr-Aug) & 2020 (Apr-Aug) \\
\hline Barrier contraception & 5580 & 5580 & 3720 & 2350 & 2280 & 2340 \\
\hline IUCD & 19 & 20 & 8 & 8 & 10 & 8 \\
\hline Oral pills & 670 & 690 & 450 & 270 & 280 & 270 \\
\hline Female sterilization surgery & 151 & 146 & 48 & 62 & 53 & 32 \\
\hline Male sterilization surgery & 17 & 14 & 2 & 10 & 6 & 0 \\
\hline
\end{tabular}

IUCD: Intrauterine contraception device 


\section{Global scenario}

WHO survey conducted in two-thirds of 103 countries between mid-May and early July 2020, reported disruptions of family planning and contraception services.

Marie Stopes International (MSI) reported that nearly 2 million fewer women received contraceptive and abortion services across 37 countries between January and June 2020 than in the same period last year, including 1.3 million alone in India (7).

United Nations Fund for Population Activities (UNFPA) statement dated 11 July 2020 revealed projections- if lockdown continues for 6 months more, then around 47 million women in low and middle-income countries may not be able to access contraception and those 7 million unintended pregnancies are expected to occur globally (8).

Even after a strong equivalent statement by the American Society of Obstetricians and Gynaecologists (ACOG) and other reproductive health professional organizations including WHO and American Medical Association (AMA) in March 2020 in favor of contraception and abortion services, most states in the United States of America (USA), had restricted or stopped these services, resulted in widespread lawsuits challenging the orders (9).

Other worst COVID-19 affected countries in Europe like Italy, France, United Kingdom also taken modified legal actions to make abortion services available by domiciliary selfmedicated medical termination of pregnancy MTP following remote consultation (10).

\section{Indian perspective}

No proper study or data authenticated by the Ministry of Health and Family Welfare (MoHFW), GoI is available on unsafe pregnancies, maternal mortality due to a lack of safe access to contraception, family planning, or ANC services in India during the pandemic. However, a few non-government organizations (NGOs) with the help of national-level Obstetric \& Gynecological federations had conducted some studies. Ipas Development Foundation (IDF), India (a nonprofit organization dedicated to preventing and managing unwanted pregnancies) conducted a recent modeling study and concluded that, between 25 March and 24 Jun 2020, an estimated 1.85 million Indian women could not terminate an unwanted pregnancy. 1.5 million of these women ( $80 \%$ of compromised abortions) were due to unavailability of drugs prescribed for medical MTP, another 20\% (almost 3,70,000) were due to lack of access to facilities, more precisely $16 \%$ due to reduced access to private health facilities and the rest $4 \%$ to public health facilities (11).

Another report by the Foundation for Reproductive Health Services India estimated that the pandemic could lead to an additional 8,34,042 unsafe abortions and 1,743 maternal deaths. These reports were alarming, as it happened even after GoI declared abortion and ANC among the essential health services on 14 April 2020 (12).

When we analyzing the data of our hospital, reduced OPD attendance during pandemic times are due to restriction on inter-district, inter-state or even local movements and lack of transportation facility available to clientele.

Monthly averages of IPD load in pandemic times in relation to that throughout the year in all the years under observation are maintained; it was possible due to the un-interrupted operational state of all departments in this hospital even with truncated manpower available due to lockdown or otherwise.

Increased OPD to IPD conversion rate even during a pandemic is mainly due to the availability of modern equipment and continuing better in-hospital management facilities around the year irrespective of COVID-19 pandemic restrictions all around.

Elevated numbers of high-risk cases managed during the period of observation are mainly attributable to the non-accessibility of proper ANC visits to nearby medical facilities in time due to pandemic restrictions.

Even after this hospital continued to attend all ANC cases requiring USG as and when asked by Obstetricians, the increasing trend for late reporting for anomaly scan during this year, more so in pandemic months may have serious health and legal hassles in the future. As stated in the MTP Act of 1971, abortions are legalized up to 20 weeks of gestation with specific causes (4). Thus if any congenital anomaly with possible serious physical and mental disability/abnormality after birth, is detected after 20 weeks of gestation during anomaly scan, it won't be legally tenable for termination of pregnancy even if both mother and doctor agree to that

Medical Termination of Pregnancy Act of 1971 says medical-method MTP can be prescribed by authorized medical practitioners till 7 weeks of intrauterine pregnancy (4). The trend of lesser numbers of medical methods and higher surgical methods for first-trimester MTP during pandemic days are mainly attributable to late reporting of patients with unwanted pregnancy due to non-accessibility of required medical consultations or non-availability of medical MTP drugs in time in their locality of residence.

Even the lesser numbers of both male and female sterilization surgeries are due to COVID pandemic restrictions imposed.

\section{Recommendations- remedial measures COVID-19 and pregnancy}

Though a few discrete cases of transplacental transmission of novel Coronavirus published, to date, the exact and extent of its effects on pregnancy are not well established. Thus, all 
pregnancies should be planned and services related to them are of utmost importance. IPC should be continued according to WHO guidelines for everyone including pregnant women (13).

\section{Safe methods of contraception during the pandemic}

All modern contraceptive methods are safe to use even in the COVID-19 pandemic (14). The couple should decide about the contraceptive method depending on family size; preferably long-acting/ permanent methods and they should able to access health care providers in person or at least through telephone/online (15). Options for the availability of condoms, OCPs, injectable or emergency contraceptive pills should be made to nearby pharmacies/drug shops even without prescriptions (16).

\section{Policymakers and service providers}

Maintaining essential health services is a great challenge in the present COVID-19 pandemic scenario, but successful implementation of strategies is the key to overcome the problems (17). All obstetrics and family planning services providing sexual, reproductive health services should be maintained for all concerned at all times, supplemented with the usage of telephonic/digital consultations, maintenance of human, financial resources and supply chain of essentials as per WHOinterim guidance and FIGO statement dated 13 April 2020 $(17,18,5)$.

All service providers should make arrangements for contraception counseling, inducting contraception initiation, assess the risk of pregnancy, contraception continuation, and contraception change/discontinuation as part of telemedicine consultation aspects.

\section{Role of government and non-government organizations}

Short-term interventions like facilitating coordination, participation, and consultation of maternal health and other sexual, reproductive health services can be done. Limitation of transmission of COVID-19 in pregnant women at all levels including community level is required. Long-term interventions are required to be sought by strengthening the health care system and extending strategies for maintaining sexual, reproductive rights, and comprehensive maternal-newborn care at the national and state level even in pandemic epicenters by any means inclusive of social media, radio, television talkshows, etc. (18).

\section{Conclusion}

In this study, a lot of immediate hazardous effects related to women's sexual and reproductive life were noted in this single secondary level care hospital experience catering to a specific population during the pandemic period even with uninterrupted availability of services in this hospital in all aspects. This result is alarming, as even after guidance/statements made by the government agencies and other world organizations related to women's health on the continuation of contraception, family planning, and safe motherhood services, these are being availed by all concerned sub-optimally in the pandemic situation. The situation is presumably worse in rural areas of mid and low-income states or countries.

As a few ill-effects on maternal reproductive and sexual life noticed in the study, it is recommended to implement continuation of 'clinical' working protocol related to its services with all safety precautions by HCWs even during pandemic times to avoid larger women health disaster in near future.

Alternatively, or in addition, extensive telephonic consultation or usage of social media platforms can be used to outreach maternity services whenever possible through participation of medical and administrative authorities are of utmost importance in this regard as stated in recommendations, so that all services can be delivered to clienteles.

Though this study had compared data of previous years in the same center, it would have been even better if studies can be done comparing data of other similar centers in the future to validate the statements notified.

\section{Acknowledgments: None}

Competing interest/ Conflicts of interest Statement: The authors declare that they have no competing interests.

Funding: No funding sources

Ethics approval and consent to participate: This article does not contain any research/studies with human participants and/or animals performed by any of the authors. However, the study was reviewed by the ethics committeel IRB of Military Hospital, Pathankot, India (Ethics approval reference No. 05/EC/IRB/2020 dated 07 September 2020). Informed consent and approval were obtained for retrospective study using data from hospital medical records before the study and as per the principles outlined in the Declaration of Helsinki (World Medical Association. Declaration of Helsinki: ethical principles for medical research).

Availability of data and materials: The data supporting this study is available through the corresponding author upon reasonable request.

Authors' contributions: $J B$ and AN raised the presented idea. All authors designed the study. JB conducted the analyses. JB, $G S$, and AN developed the first draft of the manuscript. All authors contributed to the writing of the paper, and have read and approved the final manuscript. JB, SP, and AN participated in data analysis, interpretation, and draft revision. JB, GS, and AN participated in data collection and result interpretation. All authors assisted with data collection and analysis. All authors designed the study and critically revised the manuscript. All authors read and approved the final manuscript.

\section{References}

1. Maternal Health Division. MoHFW, GoI. Guidelines: Guidelines for Antenatal Care and Skilled Attendance at 
Birth by ANMs/LHVs/SNs, April 2010. Available at: http://www.nrhmorissa.gov.in/writereaddata/Upload/Gui delines/Guidelines for ANC and SAB by ANMS, LHVs, SNs.pdf.

2. World Health Organization. Publication data: WHO recommendations on antenatal care for a positive pregnancy experience, 2016. Available at: https://apps.who.int/iris/ bitstream/handle/10665/250796/9789241549912eng.pdf; jsessionid $=5809570 \mathrm{C} 18 \mathrm{ED} 2 \mathrm{~A} 75 \mathrm{DE} 8 \mathrm{E} 736 \mathrm{BD} 75$ $5 E 4 A D$ ? sequence $=1$.

3. Sample Registration System. Registrar General of India. Vital Statistics Division. Special Bulletin: Maternal mortality in India 2014-16, May 2018. Available at: https:// cessusindia.gov.in/vital_statistics/SRS_Bulletins/MMR\% 20Bulletin-2014-16.pdf.

4. National Health Mission, MoHFW, GoI. Guidelines: Comprehensive Abortion Care. Training and Service Delivery Guidelines, Second Edition, 2018. Available at: https://www.ipasdevelopementfoundation.org/resourceFil es/72201903275732.pdf.

5. International Federation of Gynecology and Obstetrics. Statement: COVID-19 Contraception and Family Planning, 13 April 2020. Available at: https:/figo.org/ covid-19-contraception-family-planning.

6. International Federation of Gynecology and Obstetrics. Statement: Safe Motherhood and COVID-19, 30 March 2020. Available at: https://www.figo.org/sites/default/ files / $2020-04 / 30.03 .30 \% 20$ - \% 20 F I G O \% 20 Statement $\% 20$ on $\% 20$ Safe $\% 20$ Motherhood $\% 20$ and $\% 20 \mathrm{C}$ OVID-19\%20EN.pdf.

7. Marie Stopes International. Press Release: The impact of COVID-19, 04 April 2020. Available at: https://www. mariestopes.org/about-us/media-centre/.

8. United Nations Fund for Population Activities. Statement: Peace in the home: Safeguarding health and rights of women and girls- even during COVID-19, 11 July 2020. Available at: https://unfpa.org/press/peace-home-safeguarding-health-and-rights-women-and-girls$\% \mathrm{E} 2 \% 80 \% 93$-even-during-covid- 19 . Accessed on 20 September 2020.

9. Bayefsky MJ, Bartz D, Watson KL. Abortion during the Covid-19 Pandemic-Ensuring Access to an Essential Health Service. N Engl J Med. 2020;382(19): e47. Doi: 10.1056/NEJMp2008006.

10. Rocca-Ihenacho L, Alonso C. Where do women birth during a pandemic? Changing perspectives on Safe Motherhood during the COVID-19 pandemic. J Glob
Health Sci. 2020;2(1):e4. Doi: 10.35500/jghs.2020.2.e4.

11. Ipas Development Foundation. Publications: Compromised Abortion Access due to COVID-19, A model to determine impact of COVID-19 on women's access to abortion, 2020. Available at: https://www.ipasdevelopementfoundation.org/publications/compromised-abortion-access-due-to-covid-19-a-model-to-determine-impact-ofcovid-19-on-women-s-access-to-abortion.html.

12. Minister of Health and Family Welfare, GoI. Guidance Note: Guidance Note on Provision of Reproductive, Maternal, Newborn, Child, Adolescent Health Plus Nutrition $(\mathrm{RMNCAH}+\mathrm{N})$ services during \& post COVID19 Pandemic, 14 April 2020. Available at: https://www. mohfw.gov.in/pdf/GuideanceNoteonProvisionofessential RMNCAHNServices24052020.pdf

13. World Health Organization. Q\&As on COVID-19 and related health topics, 31 March 2020. Available at: www.who.int/emergeencies/diseases/novel-coronavirus2019/question-and-answers-hub/q-a-detail/q-a-coronaviruses.

14. Grandi G, Facchinetti F, Bitzer J. The gendered impact of coronavirus disease (COVID-19): do estrogens play a role? Eur J Contracept Reprod Health Care. 2020; 25(3):233-34. Doi: 10.1080/13625187.2020.1766017.

15. World Health Organization. Q\&As on COVID-19 and related health topics, 06 April 2020. Available at: https:// www.who.int/emergencies/diseases/novel-coronavirus2019/question-and-answers-hub/q-a-detail/contraceptionfamily-planning-and-covid-19.

16. Ferreira-Filho ES, de Mello NR, Sorpresso ICE, Bahamondes L, Simões RDS, Soares- Júnior JM, et al Contraception and reproductive planning during the COVID-19 pandemic. Expert Rev Clin Pharmacol. 2020; 13(6):615-22. Doi:10.1080/17512433.2020.178273 8.

17. World Health Organization. Interim Guidance: Maintaining essential health services: operational guidance for the COVID-19 context, 01 June 2020. Available at: https:// apps.who.int/iris/bitstream/handle/10665/332240 /WHO2019-nCoV-essential_health_services-2020.2-eng.pdf?sequence $=1 \&$ is Allowed $=\mathrm{y}$.

18. United Nations Fund for Population Activities. Interim technical brief: Sexual and Reproductive health and rights, Maternal and newborn health \& COVID-19,23 March 2020. Available at: https://www.unfpa.org/sites/ default/files/resource-pdf/COVID-19_Preparedness and_Response_-_UNFPA_Interim_Technical_Briefs Maternal_and_Newborn_Health_-23_March_2020_.pdf. 